\title{
Pilot scale evaluation of mine water (MW) as a cooling medium
}

\author{
JS Swart* and JP Engelbrecht \\ Water and Environmental Technology, Sasol Technology R\&D, PO Box 1, SASOL One, Sasolburg 1947, South Africa
}

\begin{abstract}
Sasol One abstracts large volumes of water from various sources, such as the Zuikerbosch \& Vaal River for various applications including make-up to the cooling water systems. In an attempt to evaluate the use of underground MW as an alternative cooling medium, two pilot-scale cooling towers (CTs) were used. Data of five runs (3 weeks each) at different linear flow velocities (LFVs) and cycles of concentration (COC) were obtained. A prescribed chemical treatment program from a local supplier was also evaluated. Mild steel corrosion coupons and heat exchanger tubes were used to monitor the fouling, scaling and corrosion rates. An experimental design program was followed to determine the layout of the different experimental runs.

The respective indices indicate the presence of low scaling and corrosion rates in the CTs which correspond well with that obtained from the analyses of the coupons and heat exchanger tubes ( 1.5 to $11.0 \mathrm{mg} / \mathrm{dm}^{2} / \mathrm{d}$ and 0.04 to $0.21 \mathrm{~mm} / \mathrm{y}$, respectively). In addition, the fouling rates ( 2.8 to $27 \mathrm{mg} / \mathrm{dm}^{2} / \mathrm{d}$ ) obtained during the five runs indicate the presence of sessile bacteria in the system. According to the supplier, the total cost of the chemical treatment program used during the pilot-scale test work is comparable to the current cost for the commercial cooling systems at Sasol One.

It is evident from the results obtained during this study that the use of underground MW as a cooling medium is a viable option. However, the work conducted in this study was only a first effort and it is possible that the high levels of sulphate (up to $966 \mathrm{mg} /$ $\ell$ ) in the make-up water could result in concrete corrosion, which could have a detrimental effect on the integrity of the cooling tower structures. In addition, the variability in the MW quality, which was not considered during the experimental period, could be problematic since it will complicate the chemical treatment of this water in a full scale cooling tower system.
\end{abstract}

\section{Introduction}

Sasol One abstracts large volumes of water from various sources, such as the Zuikerbosch \& Vaal River for various applications including make-up to the cooling water systems. The underground mine water is of a poor quality since it contains high concentrations of salts. Possible uses for this water were investigated by the Water and Environmental Technology (WET R\&D) e.g. the use of this water as cooling water.

An experimental design program was followed to determine the layout of the different experimental runs. This was done in collaboration with the Chemstat group (Process Development) at Sasol Technology, R\&D. The statistical analyses of the data were done by means of analyses of variance and regression methods to investigate the individual and interaction effects of the factors (cycles of concentration, COC, and linear flow velocity, LFV) on the responses (fouling, scaling and corrosion rates). The rationale for using an experimental design program to determine the variables (LFV and COC) is beneficial since it limited the amount of experimental runs required for reliable results en by doing so, reduced the time required for the test work. It is important to note that the variability of the MW quality was not taken into consideration during this study.

The results obtained during this study were statistically analysed and used to compare the degree of fouling, scaling and corrosion during different runs. The efficiency of a prescribed chemical program recommended by Buckman Laboratories was also evaluated during this study. In addition, the supplier also determined the cost of the chemical treatment program used.

\section{Experimental procedure}

This research was conducted as a result of a previous study

This paper was originally presented at the 2004 Water Institute of South Africa (WISA) Biennial Conference, Cape Town, South Africa, 2-6 May 2004.

* To whom all correspondence should be addressed.

嘼+2716 9602895 ; fax:+2711 522 4678; e-mail: joey.swart@sasol.com conducted on laboratory scale CTs for the evaluation of the use of MW as a cooling medium, which resulted in promising results (Raijmakers, et al, 2001).

Two pilot-scale CTs were operated using a prescribed chemical treatment program from a local supplier and MW was used as make-up to the cooling towers. This study includes data of five respective runs at different LFVs and COCs. Each run was executed over a period of three weeks.

Determination of the COC was based on potassium, chloride and conductivity analyses and controlled by means of a blow down system.

The $\mathrm{pH}$ of the recirculation water was adjusted to maintain a $\mathrm{pH}$ of 8.2 to achieve optimal performance of the control chemicals used in the various tests. Sodium hydroxide and hydrochloric acid were used for $\mathrm{pH}$ adjustment to optimise the effectiveness of the treatment program. Mild steel corrosion coupons and heat exchanger tubes were used to monitor the fouling, scaling and corrosion rates.

The experimental conditions of the CTs:

CT Inlet Temperature: $\quad 40-45^{\circ} \mathrm{C}$

CT Outlet Temperature: $\quad 32-35^{\circ} \mathrm{C}$

Delta T:

$8-10^{\circ} \mathrm{C}$

System volume: $\quad 100 \ell$ (excluding COC)

The operational conditions for the experimental design program for the different runs are summarised below:

\begin{tabular}{|c|c|c|c|c|}
\hline $\begin{array}{c}\text { Respective } \\
\text { runs }\end{array}$ & $\begin{array}{c}\text { LFV in } \\
\mathbf{H E}^{*} \text { tubes } \\
(\mathbf{m} / \mathbf{s})\end{array}$ & $\begin{array}{c}\text { LFV in } \\
\mathbf{C R}^{* *} \\
(\mathbf{m} / \mathbf{s})\end{array}$ & $\begin{array}{c}\text { Recircu- } \\
\text { lation flow } \\
\text { rate }(\boldsymbol{\ell} / \mathbf{h})\end{array}$ & coc \\
\hline 1 & 1 & 0.9 & 600 & 6 \\
2 & 0.7 & 0.56 & 400 & 4 \\
3 & 1 & 0.9 & 600 & 2 \\
4 & 0.35 & 0.22 & 200 & 6 \\
5 & 0.35 & 0.22 & 200 & 2 \\
\hline
\end{tabular}




\begin{tabular}{|c|c|c|c|c|}
\hline \multicolumn{5}{|c|}{$\begin{array}{l}\text { TABLE } 1 \\
\text { Variability in the make-up water (MW) quality of the pilot scale } \\
\text { CTs during the experimental period }\end{array}$} \\
\hline Constituent & Units & Average & $\begin{array}{l}\text { Standard } \\
\text { deviation }\end{array}$ & $\begin{array}{c}\text { No. of } \\
\text { analyses } \\
\text { conducted } \\
\text { during the } \\
\text { experimental } \\
\text { period }\end{array}$ \\
\hline pH & - & 8.65 & 0.283 & 97 \\
\hline Conductivity & $\mathrm{mS} / \mathrm{cm}$ & 3061 & 158 & 96 \\
\hline $\mathrm{Cl}$ & $\mathrm{mg} / \ell$ & 94 & 6.799 & 96 \\
\hline $\mathrm{PO}_{4}$ & $\mathrm{mg} / \mathrm{l}$ & 1 & 0.373 & 39 \\
\hline $\mathrm{SO}_{4}^{4}$ & $\mathrm{mg} / \ell$ & 621 & 115 & 93 \\
\hline M- Alkalinity & $\mathrm{mg} / \ell$ as $\mathrm{CaCO}_{3}$ & 967 & 81 & 95 \\
\hline SS & $\mathrm{mg} / \ell$ & 9 & 6.7 & 38 \\
\hline Сa & $\mathrm{mg} / \ell$ & 18 & 2.5 & 95 \\
\hline Mg & $\mathrm{mg} / \mathrm{l}$ & 31 & 6.5 & 96 \\
\hline $\mathrm{Na}$ & $\mathrm{mg} / \mathrm{l}$ & 726 & 111 & 96 \\
\hline K & $\mathrm{mg} / \ell$ & 12 & 3.215 & 96 \\
\hline TDS & $\mathrm{mg} / \mathrm{l}$ & 1978 & 116 & 39 \\
\hline $\mathrm{SiO}_{2}$ & $\mathrm{mg} / \mathrm{l}$ & 13 & 1.153 & 18 \\
\hline $\mathrm{NH}_{3}^{2}$ & $\mathrm{mg} / \mathrm{l}$ & 0.35 & 0.228 & 19 \\
\hline
\end{tabular}

Results and discussion

\section{Corrosion, scaling and fouling potential}

The quality of the Sigma mine water used during this study varied significantly over the experimental period (eight months). Table 1 summarises the upper and lower limits of the various constituents present in the MW.

It was evident from the data depicted in Table 1 that the variation in the $\mathrm{SO}_{4}$ and $\mathrm{Na}$ concentrations were more significant $(18.5 \%$ and $15 \%$, respectively with regard to the standard deviation) when compared to the other constituents during the experimental period.

The average values of the indices obtained during the different runs are summarising in Table 2.

The fouling, scaling and corrosion rates obtained during the respective runs are summarised in Table 3.

Results of the respective indices depicted in Table 2 indicate the presence of relatively low scaling and very low corrosion potential in the CTs. These results compare well with the low scaling and corrosion results obtained (Table 3 ) since the indices are an excellent tool to predict the scaling and corrosion potential of a given water.

It is important to note that the fouling and scaling rates obtained from the heat exchanger tubes were lower when compared to that of the coupons. This can be attributed to the lower LFV in the coupons since a portion of the recirculation flow passing through the heat exchangers was routed to the biocells and was therefore not passing through the coupon racks. The corrosion rates, however, were slightly higher in the heat exchanger tubes when compared to the results obtained from the coupons. It is important to note that the fouling, scaling and corrosion rates achieved during this study were in some cases better than that of the Sasol Standards.

The fouling on the coupons and heat exchanger tubes were analysed using XRD and was found to be predominately goethite (hydrated iron oxide). The presence of iron in the recirculation water most probably as a resulted of the carbon steel fans.

According to Buckman Laboratories, the total cost of the chemical treatment program used during the pilot-scale test work is approximately R661/Ml (based on the average quality of the MW) which compares well with the current cost for the commercial Process Cooling Towers at Sasol One.

\section{Microbial analysis}

sulphur reducing bacteria (SRB) was slug dosed twice a week in the sumps of the CTs for microbial control. A scale inhibitor for $\mathrm{CaCO}_{3}$ control and a corrosion inhibitor for high pitting conditions were continuously dosed in the recirculation water of the towers. A fourth product was also continuously dosed to provide iron dispersion in the system.

Conventional plate count procedures were used to determine the microbial population during the experimental period. The population dynamics were monitored three times a week during each run by means of total plate counts (TPC) and Pseudomonas counts, which give an indication of the planktonic bacteria in the system. In addition, biocells were positioned in the sumps of the towers to determine the degree of biofouling in the cooling systems.
The microbial analysis is summarised in Table 4.

It was evident from the results depicted in Table 4 that the TPC in the CTs was relatively low, which indicates the presence of small amounts of planktonic micro-organisms in the system. In addition, the low biofouling and the fouling rates obtained during the five runs indicate the presence of very little sessile bacteria in the system. These results also proved the affectivity of the oxidising biocide to provide an effective treatment against the growth of micro-organisms in the CTs. 
TABLE 3

Average results obtained during the five experimental runs

\begin{tabular}{|c|c|c|c|c|c|c|c|c|}
\hline \multirow[t]{6}{*}{ Operating Conditions } & \multicolumn{5}{|c|}{ LFV (m/s): Heat Exchanger Tubes } & & & \\
\hline & 1 & 0.7 & 1 & 0.35 & 0.35 & & & \\
\hline & \multicolumn{5}{|c|}{ LFV (m/s): Corrosion Racks } & & & \\
\hline & 0.9 & 0.56 & 0.9 & 0.22 & 0.22 & & & \\
\hline & \multicolumn{5}{|c|}{ COC } & & & \\
\hline & 6 & 4 & 2 & 6 & 2 & & & \\
\hline & \multicolumn{5}{|c|}{ Coupon Results } & Sasol std** & PCTs $s^{\star \star *}$ & SGL CTs**** \\
\hline Fouling (mg/dm²/d) & 16.226 & 3.772 & 10.180 & 26.512 & 19.364 & 20 & 56.41 & 54.27 \\
\hline Scaling (mg/dm²/d) & 5.380 & 3.013 & 4.171 & 11.201 & 9.647 & 2 & 3.48 & 7.91 \\
\hline \multirow[t]{2}{*}{ Corrosion (mm/y) } & 0.055 & 0.040 & 0.050 & 0.203 & 0.174 & 0.2 & 0.26 & 0.24 \\
\hline & \multicolumn{5}{|c|}{ HE* Tube Results } & Sasol std** & $N / A^{* \star \star \star}$ & $N / A^{* \star * *}$ \\
\hline Fouling (mg/dm²/d) & 3.939 & 3.055 & 56.41 & 54.27 & 3.531 & 20 & & \\
\hline Scaling $\left(\mathrm{mg} / \mathrm{dm}^{2} / \mathrm{d}\right)$ & 3.488 & 2.855 & 3.48 & 7.91 & 4.834 & 2 & & \\
\hline Corrosion (mm/y) & 0.190 & 0.123 & 0.26 & 0.24 & 0.205 & 0.2 & & \\
\hline
\end{tabular}

$* \mathrm{HE}=$ Heat exchanger

**Sasol Standard = standards set by Sasol as an indication of the fouling, scaling and corrosion potential of the recirculation water in the cooling systems.

*** Average fouling, scaling and corrosion rates obtained in the Process Cooling Towers at Sasol One during the last year

**** Average fouling, scaling and corrosion rates obtained in the F and G (SGL) Cooling Towers at Sasol

One during the last year

$* * * * \mathrm{~N} / \mathrm{A}=$ Not Applicable

TABLE 4

Average microbial counts during the experimental period

\begin{tabular}{|c|c|c|c|}
\hline Operating parameters & $\begin{array}{c}\text { TPC } \\
\text { (counts/1 me) }\end{array}$ & $\begin{array}{l}\text { Pseudomonas } \\
\text { (counts/1 m } / \text { ) }\end{array}$ & $\begin{array}{c}\text { Biocell } \\
(\mathrm{mg})\end{array}$ \\
\hline \multicolumn{4}{|c|}{ Make-up water } \\
\hline $\begin{array}{l}\text { LFV }\left(\mathrm{HE}^{*} \text { tubes }\right)=1 \mathrm{~m} / \mathrm{s} ; \mathrm{LFV}\left(\mathrm{CR}^{* *}\right)=0.9 \mathrm{~m} / \mathrm{s} ; \mathrm{COC}=6 \\
\mathrm{LFV}\left(\mathrm{HE}^{*} \text { tubes }\right)=0.7 \mathrm{~m} / \mathrm{s} ; \mathrm{LFV}\left(\mathrm{CR}^{* *}\right)=0.56 \mathrm{~m} / \mathrm{s} ; \mathrm{COC}=4 \\
\mathrm{LFV}\left(\mathrm{HE}^{*} \text { tubes }\right)=1 \mathrm{~m} / \mathrm{s} ; \mathrm{LFV}\left(\mathrm{CR}^{* *}\right)=0.9 \mathrm{~m} / \mathrm{s} ; \mathrm{COC}=2 \\
\mathrm{LFV}\left(\mathrm{HE}^{*} \text { tubes }\right)=0.35 \mathrm{~m} / \mathrm{s} ; \mathrm{LFV}\left(\mathrm{CR}^{* *}\right)=0.22 \mathrm{~m} / \mathrm{s} ; \mathrm{COC}=6 \\
\mathrm{LFV}\left(\mathrm{HE}^{*} \text { tubes }\right)=0.35 \mathrm{~m} / \mathrm{s} ; \mathrm{LFV}\left(\mathrm{CR}^{* *}\right)=0.22 \mathrm{~m} / \mathrm{s} ; \mathrm{COC}=2\end{array}$ & $\begin{array}{l}1.31 \times 10^{3} \\
1.20 \times 10^{3} \\
1.22 \times 10^{3} \\
1.31 \times 10^{3} \\
1.36 \times 10^{3}\end{array}$ & $\begin{array}{l}1.10 \times 10^{3} \\
1.00 \times 10^{3} \\
1.12 \times 10^{3} \\
1.11 \times 10^{3} \\
1.22 \times 10^{3}\end{array}$ & $\begin{array}{l}\text { N/A } \\
\text { N/A } \\
\text { N/A } \\
\text { N/A } \\
\text { N/A }\end{array}$ \\
\hline \multicolumn{4}{|c|}{ Recirculation water } \\
\hline $\begin{array}{l}\mathrm{LFV}\left(\mathrm{HE}^{*} \text { tubes }\right)=1 \mathrm{~m} / \mathrm{s} ; \mathrm{LFV}\left(\mathrm{CR}^{* *}\right)=0.9 \mathrm{~m} / \mathrm{s} ; \mathrm{COC}=6 \\
\mathrm{LFV}\left(\mathrm{HE}^{*} \text { tubes }\right)=0.7 \mathrm{~m} / \mathrm{s} ; \mathrm{LFV}\left(\mathrm{CR}^{* *}\right)=0.56 \mathrm{~m} / \mathrm{s} ; \mathrm{COC}=4 \\
\mathrm{LFV}\left(\mathrm{HE}^{*} \text { tubes }\right)=1 \mathrm{~m} / \mathrm{s} ; \mathrm{LFV}\left(\mathrm{CR}^{* *}\right)=0.9 \mathrm{~m} / \mathrm{s} ; \mathrm{COC}=2 \\
\mathrm{LFV}\left(\mathrm{HE}^{*} \text { tubes}\right)=0.35 \mathrm{~m} / \mathrm{s} ; \mathrm{LFV}\left(\mathrm{CR}^{* *}\right)=0.22 \mathrm{~m} / \mathrm{s} ; \mathrm{COC}=6 \\
\mathrm{LFV}\left(\mathrm{HE}^{*} \text { tubes }\right)=0.35 \mathrm{~m} / \mathrm{s} ; \mathrm{LFV}\left(\mathrm{CR}^{* *}\right)=0.22 \mathrm{~m} / \mathrm{s} ; \mathrm{COC}=2 \\
\text { Process Cooling Towers at Sasol One } \\
\text { SGL Cooling Towers at Sasol One }\end{array}$ & $\begin{array}{l}3.7 \times 10^{4} \\
3.4 \times 10^{4} \\
3.1 \times 10^{4} \\
4.2 \times 10^{4} \\
3.9 \times 10^{4} \\
5.0 \times 10^{5} \\
4.1 \times 10^{5}\end{array}$ & $\begin{array}{l}2.6 \times 10^{4} \\
3.1 \times 10^{4} \\
2.5 \times 10^{4} \\
3.6 \times 10^{4} \\
2.9 \times 10^{4} \\
3.7 \times 10^{4} \\
3.2 \times 10^{4}\end{array}$ & $\begin{array}{l}3.53 \\
3.41 \\
3.40 \\
3.39 \\
3.68\end{array}$ \\
\hline $\begin{array}{l}{ }^{*} \mathrm{HE}=\text { heat exchanger } \\
{ }^{* *} \mathrm{CR}=\text { coupon rack } \\
\text { N/A = not applicable }\end{array}$ & & & \\
\hline
\end{tabular}




\begin{tabular}{|l|c|c|c|c|c|}
\hline \multicolumn{7}{|c|}{$\begin{array}{c}\text { TABLE 5 } \\
\text { Analysis of variance for the response scaling obtained from } \\
\text { the coupon data }\end{array}$} \\
\hline Source & $\begin{array}{c}\text { Sum of } \\
\text { squares }\end{array}$ & DF & $\begin{array}{c}\text { Mean } \\
\text { square }\end{array}$ & FValue & p-value \\
& 40.81 & 1 & 40.81 & 10.09 & 0.0337 \\
Model & 40.81 & 1 & 40.81 & 10.09 & 0.0337 \\
A - LFV & 16.18 & 4 & 4.05 & & \\
Residual & 16.16 & 3 & 5.39 & 182.39 & 0.0544 \\
Lack of Fit & 0.030 & 1 & 0.030 & & \\
Pure Error & 57.00 & 5 & & & \\
Cor Total & 0.72 & & & & \\
\hline R-Squared: & 0.72 & & & \\
\hline
\end{tabular}

\begin{tabular}{|l|c|c|c|c|c|}
\hline \multicolumn{7}{|c|}{ TABLE 6} \\
Analysis of variance for the corrosion response obtained from \\
the coupon data \\
\hline Source & $\begin{array}{c}\text { Sum of } \\
\text { squares }\end{array}$ & DF & $\begin{array}{c}\text { Mean } \\
\text { square }\end{array}$ & FValue & p-value \\
\hline Model & 0.031 & 1 & 0.031 & 14.12 & 0.0198 \\
A - LFV & 0.031 & 1 & 0.031 & 14.12 & 0.0198 \\
Residual & $8.745 \mathrm{E}-003$ & 4 & $2.186 \mathrm{E}-003$ & & \\
Lack of Fit & $8.737 \mathrm{E}-003$ & 3 & $2.912 \mathrm{E}-003$ & 364.03 & 0.0385 \\
Pure Error & $8.000 \mathrm{E}-006$ & 1 & $8.000 \mathrm{E}-006$ & & \\
Cor Total & 0.040 & 5 & & & \\
\hline R-Squared: & 0.78 & & & & \\
\hline
\end{tabular}

An experimental design ( $2^{2}$ factorial, 2 centre points) was used to investigate the effect of the two factors, COC and different LFV on the response variables. The three response variables that were measured were fouling, scaling and corrosion rates.

The statistical analyses of the data were performed by means of analysis of variance and regression methods to investigate the individual and interaction effects of the factors on the responses. The results of the statistical analyses are discussed separately for each response and indicate whether it was coupon or heat exchanger data. The statistical data are summarised in Tables 5, 6 and 7 and in Figures 1, 2 and 3.

The analysis for the response fouling obtained from the coupon and heat exchanger data indicated that the factors LFV and COC didn't have a statistically significant effect on the degree of fouling. In addition, the results obtained from the heat exchanger data were also negligible since the factors LFV and COC didn't have a statistically significant effect on the scaling rates.

The p-value of 0.0337 in Table 5 indicates that LFV has a statistical significant effect on scaling. For an effect to be statistically significant, the p-value of that specific effect should be less than 0, 05 (5\% Significance Level). A smaller p-value will result in a more statistically significant effect. The effect is visualised in Figure 1 where it is clear that when LFV was increased from $0.22 \mathrm{~m} / \mathrm{s}$ to $0.90 \mathrm{~m} / \mathrm{s}$, scaling decreased significantly.

The p-value of 0.0198 indicates that LFV has a statistical significant effect on corrosion (Table 6). It is evident from Figure 2 that when LFV was increased from 0.22 to $0.90 \mathrm{~m} / \mathrm{s}$, the corrosion rate decreased significantly.

From the p-values in Table 7, it is evident that the COC (p-value $=0.0237$ ) and LFV to a lesser extent (p-value $=0.0560)$, have a statistically significant effect on the degree of corrosion. Figure 3(a) indicates that an increase of LFV from 0.35 to $1.00 \mathrm{~m} / \mathrm{s}$ resulted in a significant decrease of corrosion rates compared to Figure 3(b) where the increase of COC from 2 to 6 cycles have shown a significant increase in the corrosion rates.

The R-Squared value of 0.90 in Table 7 indicates that this two-factor interaction model explains $90 \%$ of the total variation in the data (very good model fit). An R-Squared value ranges from 0 to 1 and the closer it is to 1 , the better the model describes or fit the data.

To summarise the pilot scale CT data, it is evident that fouling (in a lesser amount), scaling and corrosion decreased with increasing LFV and decreasing COC.

\section{Conclusions and recommendations}

Results of the respective indices indicate a slight potential of scaling and very low corrosion rates in the CTs which correspond well with that obtained from the analyses of the coupons and heat exchanger tubes. 
The fouling on the coupons and heat exchanger tubes were analysed using XRD and was found to be predominately goethite (hydrated iron oxide).

To summarise the statistical data obtained, it is evident that fouling (in a lesser amount), scaling and corrosion decreased with increasing LFV and decreasing COC.

The TPC and the Pseudomonas counts in the CTs were relatively low, which indicates the presence of small amounts of planktonic microorganisms in the system. In addition, the low biofouling and the fouling rates obtained during the five runs indicate the presence of very little sessile bacteria in the system.

According to the supplier, the total cost of the chemical treatment program used during the pilot-scale test work is approximately R661/Ml (based on the average quality of the MW) which compares well with the current cost for the commercial Process Cooling Towers at Sasol One.

It is evident from the results obtained during this study that the MW as a cooling medium is a viable option. However, the work conducted in this study was only a first estimation and it is possible that the high levels of sulphate (up to $966 \mathrm{mg} / \ell$ ) in the make-up water could result in concrete corrosion, which could have a detrimental effect on the integrity of the Process Cooling Towers. In addition, the variability in the mine water quality, which was not considered during the experimental period, could be problematic since it will complicate the chemical treatment of this water in a full scale cooling tower system.

The volumes, quality and variability of Sigma underground MW during decanting is urgently required. This information will probably become available during an extensive modelling study planned for the immediate future, where after this test work will be repeated in more detail. The quality of MW used in the current work is most probably representative of a worst case scenario.

\section{Reference}

RAIJMAKERS N, SEBOKA T and STENDEN TBF (2001) Sasol Technology R\&D Status Report: Laboratory Scale Evaluation of Sigma Mine Water as Cooling Water.
DESIGN-EXPERT PIOT Scaling

$x=A: L F V$

- Design Points

Actual Factor B: $\mathrm{COC}=4.00$

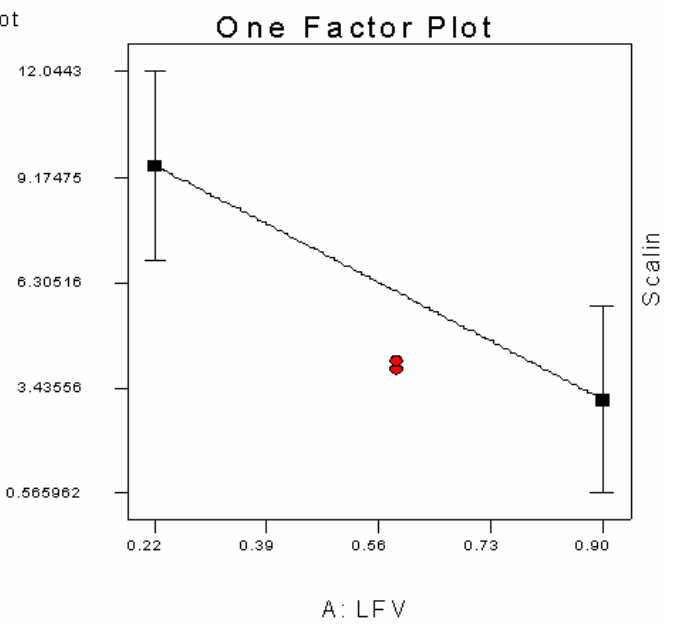

Figure 1

One factor plot showing the effect of LFV on scaling (coupon data)

DESIGN - EXPERT PIOT

Corrosion

$X=A: L F V$

- Design Points

Actual Factor

B: $\operatorname{COC}=4.00$

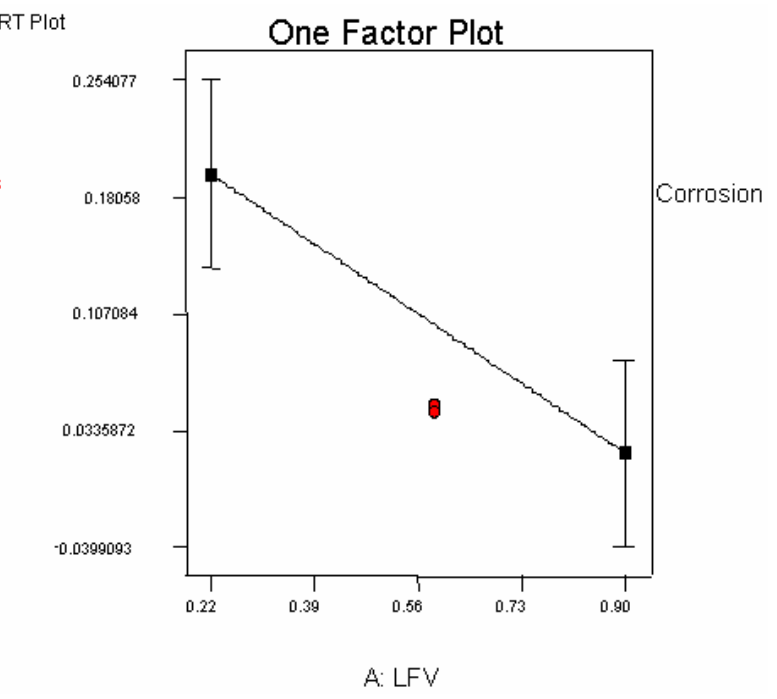

Figure 2

One factor plot showing the effect of LFV on corrosion (coupon data)
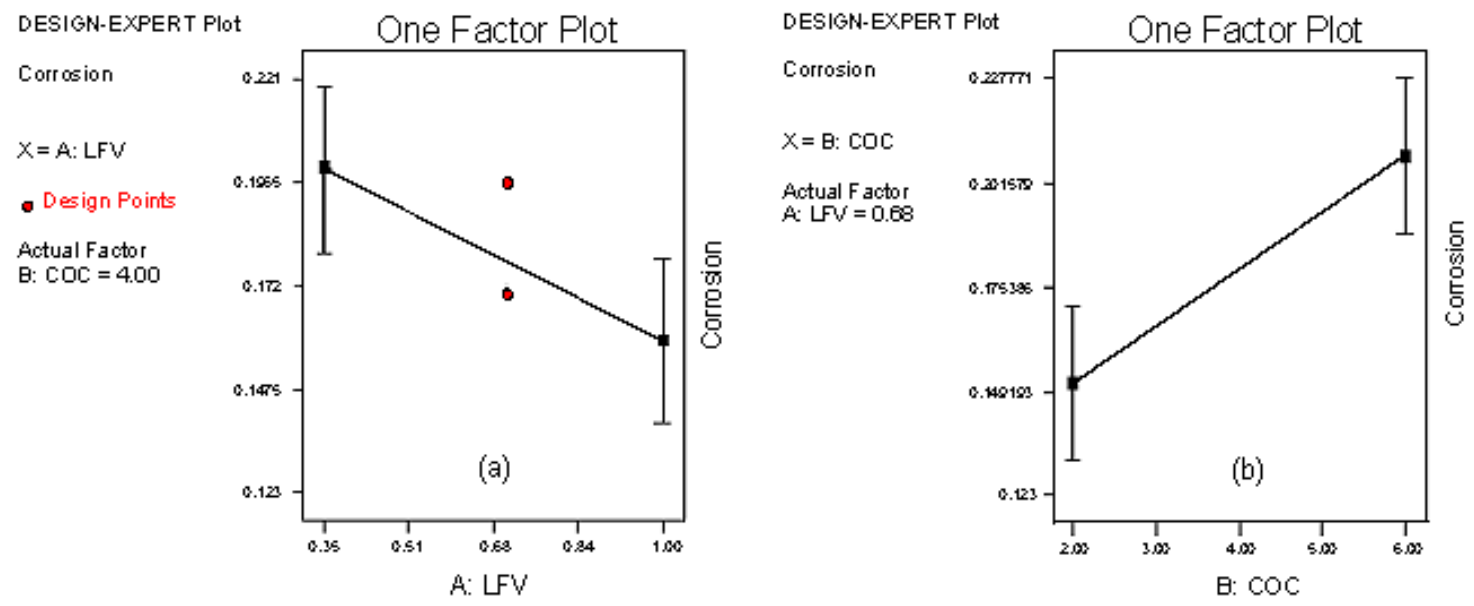

Figure 3

One factor plot showing the effect of (a) LFV on corrosion obtained from the heat exchanger tubes and (b) $\mathrm{COC}$ on corrosion obtained from the heat exchanger tubes. 